Article

\title{
Highly Graphitized Carbon Coating on SiO with a $\pi-\pi$ Stacking Precursor Polymer for High Performance Lithium-Ion Batteries
}

\author{
Shan Fang ${ }^{1,2}$, Ning $\mathrm{Li}^{1}{ }^{\text {, Tianyue Zheng }}{ }^{1}$, Yanbao Fu ${ }^{1}$, Xiangyun Song ${ }^{1}$, Ting Zhang ${ }^{1}$, \\ Shaopeng $\mathrm{Li}^{2}$, Bin Wang ${ }^{1}$, Xiaogang Zhang ${ }^{2, *}$ and Gao Liu ${ }^{1, *}$ \\ 1 Energy Storage and Distributed Resources Division, Energy Technologies Area, Lawrence Berkeley National \\ Laboratory, Berkeley, CA 94720, USA; fangshan_joy@163.com (S.F.); ningli@lbl.gov (N.L.); \\ tyzheng@lbl.gov (T.Z.); yanbaofu@lbl.gov (Y.F.); x_song@lbl.gov (X.S.); zhangting@bit.edu.cn (T.Z.); \\ wangbin0502@163.com (B.W.) \\ 2 Jiangsu Key Laboratory of Electrochemical Energy Storage Technologies, College of Material Science and \\ Engineering, Nanjing University of Aeronautics and Astronautics, Nanjing 210016, China; \\ 15150675098@163.com \\ * Correspondence: azhangxg@nuaa.edu.cn (X.Z.); gliu@lbl.gov (G.L.); Tel.: +1-510-486-7207 (G.L.)
}

Received: 25 April 2018; Accepted: 31 May 2018; Published: 4 June 2018

\begin{abstract}
A highly graphitized carbon on a silicon monoxide ( $\mathrm{SiO}$ ) surface coating at low temperature, based on polymer precursor $\pi-\pi$ stacking, was developed. A novel conductive and electrochemically stable carbon coating was rationally designed to modify the $\mathrm{SiO}$ anode materials by controlling the sintering of a conductive polymer, a pyrene-based homopolymer poly (1-pyrenemethyl methacrylate; PPy), which achieved high graphitization of the carbon layers at a low temperature and avoided silicon carbide formation and possible $\mathrm{SiO}$ material transformation. When evaluated as the anode of a lithium-ion battery (LIB), the carbon-coated $\mathrm{SiO}$ composite delivered a high discharge capacity of $2058.6 \mathrm{mAh} / \mathrm{g}$ at $0.05 \mathrm{C}$ of the first formation cycle with an initial Coulombic efficiency (ICE) of $62.2 \%$. After 50 cycles at $0.1 \mathrm{C}$, this electrode capacity was $1090.2 \mathrm{mAh} / \mathrm{g}(\sim 82 \%$ capacity retention, relative to the capacity of the second cycle at $0.1^{\circ} \mathrm{C}$ rate), and a specific capacity of $514.7 \mathrm{mAh} / \mathrm{g}$ was attained at $0.3 \mathrm{C}$ after 500 cycles. Furthermore, the coin-type full cell composed of the carbon coated $\mathrm{SiO}$ composite anode and the $\mathrm{Li}\left[\mathrm{Ni}_{0.5} \mathrm{Co}_{0.2} \mathrm{Mn}_{0.3} \mathrm{O}_{2}\right]$ cathode attained excellent cycling performance. The results show the potential applications for using a $\pi-\pi$ stacking polymer precursor to generate a highly graphitize coating for next-generation high-energy-density LIBs.
\end{abstract}

Keywords: graphite carbon; silicon monoxide; anode; coating; lithium-ion battery

\section{Introduction}

Lithium-ion batteries (LIBs), consisting of graphite and lithium cobalt oxide $\left(\mathrm{LiCoO}_{2}\right)$ electrodes, have been a major success in the consumer electronics industry due to their good stability and high performance. Higher energy density and long-term cycling stable and rechargeable LIB are needed in large-scale electrochemical energy storage systems, especially for electric vehicles and advanced power grids [1,2]. As a key component of LIBs, negative materials with improved storage capacity and thermal stability have been proposed to replacing graphite that has a theoretical capacity of only $372 \mathrm{mAh} / \mathrm{g}$. Silicon and silicon-based anode material have been attracting the most research attention due to their unparalleled theoretical capacity ( $3579 \mathrm{mAh} / \mathrm{g}$ for $\mathrm{Si}$ and $\sim 1500 \mathrm{mAh} / \mathrm{g}$ for SiO), relatively low discharge potential $\left(<0.5 \mathrm{~V}\right.$ vs. $\left.\mathrm{Li} / \mathrm{Li}^{+}\right)$, abundant reserves, and low cost $[3,4]$. However, commercial application has been impeded by drawbacks in terms of the large volume changes that occur during lithiation and de-lithiation, thus disrupting the electrode integrity and breaking up the 
solid electrolyte interface (SEI). The breakdown of the SEI layer during cycling is one of the main reasons for large capacity fading, low initial Coulombic efficiency (ICE) during cycling, and poor cycling stability [5-7].

To address these challenges, engineered nano-structuring has been reported and proven to be successful in promoting electrochemical performance. Various delicate nanostructures have been designed and fabricated, such as yolk-shell [8-10], pomegranate-like [11,12], nanotubes [13-15], and hollow spheres structure [16-18]. Although this void-in nanostructure can effectively accommodate the large volume changes and extend the cycle life, other new fundamental challenges related to the nanostructured electrodes have been introduced, including higher surface area, low tap density, complex synthesis process, and generally poor electrical properties due to the higher inter-particle resistance.

The conductive polymer and carbon coating has been demonstrated to be a feasible approach to improve the electrochemical performance of the electrode materials for lithium-ion batteries. Conductive coating layers have been reported to not only increase the electrical conductivity, but also minimize the side reactions and minimize the volume changes as an electrolyte blocking layer on the surface of the Si-based material during cycling. For example, Yu et al. successfully synthesized a stable silicon anode material via the in-situ polymerization of polyaniline (PANi) to conformal coat silicon nanoparticles, and about $550 \mathrm{mAh} / \mathrm{g}$ was obtained after 5000 cycles at $6 \mathrm{~A} / \mathrm{g}$ with a mass loading of $0.2-0.3 \mathrm{mg} / \mathrm{cm}$ [19]. Lee et al. used polyacrylonitrile (PAN) as a precursor, by limiting the pyrolysis temperature to $300-500{ }^{\circ} \mathrm{C}$ to attained the cyclization of PAN, which was achieved without carbonization while maintaining PAN's polymeric properties. This uniform coating layer on the surface of Si nanoparticles has superior performance-nearly $1500 \mathrm{mAh} / \mathrm{g}$ has been achieved after 150 cycles at a current rate of 0.1 C [20]. Park et al. reported a nitrogen-doped carbon coating for $\mathrm{SiO}$ that exhibited substantially improved specific capacity and rate performance [21]. However, long-term cycling stability and high mass loading are still needed for these silicon-based anodes for practical applications.

Here, we report using inexpensive and commercially available microparticles of silicon monoxide as a more promising electrode material for practical industrial applications. To create high stability and long-term cycling life of this silicon-based material, we describe an efficient yet easy strategy to modify the surface microstructure and electrical conductivity of $\mathrm{SiO}$ by introducing a high graphitization carbon agent to encapsulate the $\mathrm{SiO}$ at a mild temperature. The precursor, poly (1-pyrenemethyl methacrylate) (PPy) conductive polymer, was recently developed by our group as a functional conductive polymer adhesive binder [22]. The pyrene side chains of the PPy polymer form a $\pi-\pi$ stacked structure in the solid-state to promote graphitization when the polymer is carbonized. Our experimental results demonstrate that the optimal pyrolysis of this polymer leads to high graphitization carbon coatings without formation of silicon carbide. Several reasons can support this unique coating on the surface of the $\mathrm{SiO}$ as an anode electrode: (1) the homogeneous encapsulation of the $\mathrm{SiO}$ by this graphite carbon can prevent direct contact between the electrolytes and the active material to restrain the repeatable formation of the SEI membrane and unfavorable parasitic reactions; (2) the graphite carbon layer can easily accommodate the strain and severe volume changes of the $\mathrm{SiO}$ generated during the cycling; and (3) the good electronic conductivity of the coating layer can facilitate rapid electronic transport on the surface of the $\mathrm{SiO}$. The electrochemical tests indicated that the $\mathrm{SiO}$ encapsulated with this high graphitization coating layer has excellent cycling stability with high capacity and high coulombic efficiency (CE). Additionally, the full cells assembled with $\mathrm{Li}\left[\mathrm{Ni}_{0.5} \mathrm{Co}_{0.2} \mathrm{Mn}_{0.3} \mathrm{O}_{2}\right](\mathrm{NCM})$ also demonstrated an excellent cycling performance. We hope this novel surface modification method will inspire the development of high-performance Si-based anode materials. 


\section{Results and Discussion}

A schematic illustration for the synthesis of the SiO-PPy composite material is shown in Figure 1a. We synthesized SiO-PPy sub-micrometer particles in a controlled manner. Typically, $\mathrm{SiO}$ sub-micrometer particles were dispersed in the solution of PPy in tetrahydrofuran (THF) and the resulting mixture was submitted to ultrasonics and stirred (the mass ratio of SiO and PPy is 7:3). Then, the solvents were evaporated by the rotary evaporator to obtain the SiO-PPy precursors, followed by sintering at low temperatures from 400 to $600{ }^{\circ} \mathrm{C}$ in an inert atmosphere to obtain the final products, which were uniformly coated with a carbon layer on the $\mathrm{SiO}$ surface. The coating process is simple, well-controlled, and consistent.

\section{a}

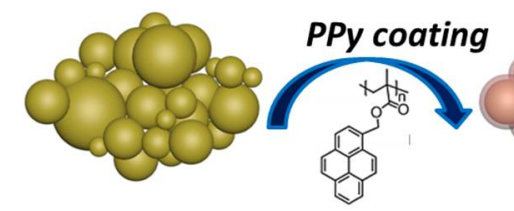

SiO
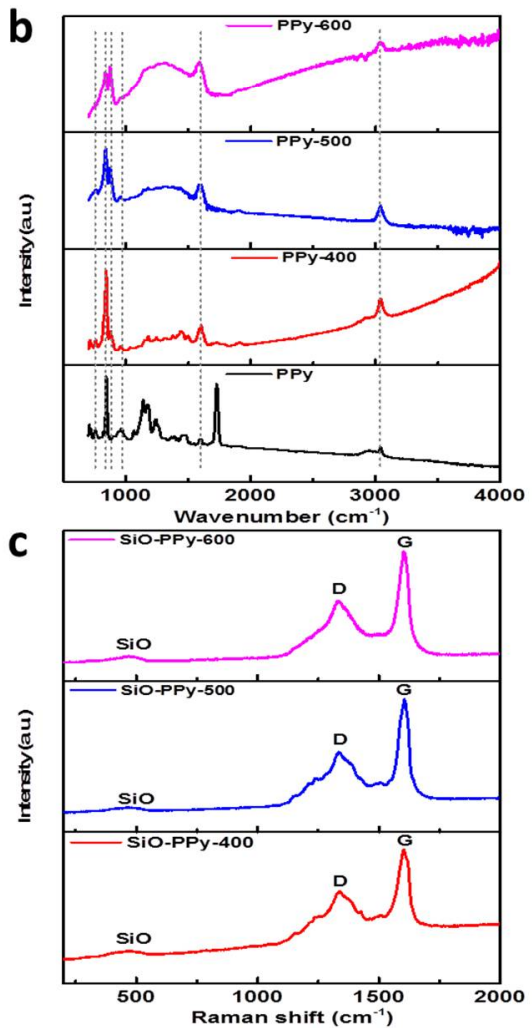
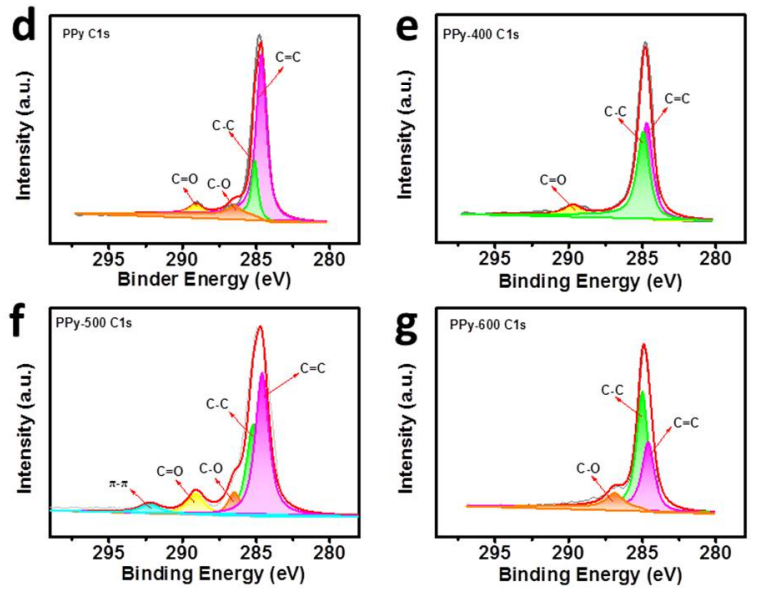

h
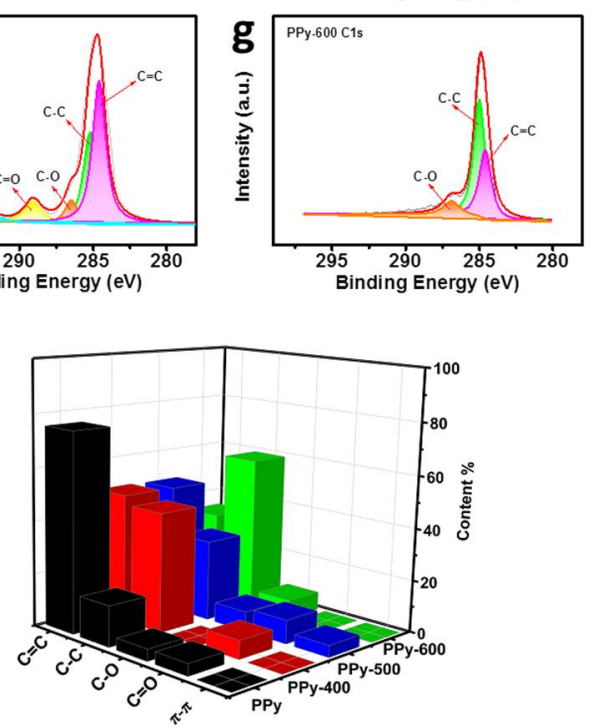

Figure 1. (a) Schematic illustrating the synthesis process of the SiO-PPy composite material sintered at different temperature; (b) Attenuated Total Reflectance Fourier transform infrared (ATR-FTIR) spectra of untreated PPy and PPy pyrolyzed at $400-600^{\circ} \mathrm{C}$; (c) Raman spectra of SiO-PPy treated at 400, 500, and $600{ }^{\circ} \mathrm{C} ;(\mathbf{d}-\mathbf{g}) \mathrm{x}$-ray photoelectron spectroscopy (XPS) spectra; and (h) the corresponding carbon bonding composition of untreated PPy and PPy pyrolyzed at $400-600{ }^{\circ} \mathrm{C}$.

Attenuated Total Reflectance Fourier transform infrared (ATR-FTIR) and Raman were first used to characterize the structure transformation of the PPy during pyrolysis. Figure $1 \mathrm{~b}$ shows the ATR-FTIR spectra of pristine PPy and PPy pyrolyzed between 400 and $600{ }^{\circ} \mathrm{C}$. PPy before pyrolysis displayed bands at $1721 \mathrm{~cm}^{-1}$ due to $\mathrm{C}=\mathrm{O}$ stretching of the ester groups, $1594 \mathrm{~cm}^{-1}$ due to the benzene skeleton 
vibration, and at $844 \mathrm{~cm}^{-1}$ due to aromatic stretching substitute. The bans at $1121 \mathrm{~cm}^{-1}$ is assigned to $\mathrm{C}-\mathrm{O}-\mathrm{C}$ stretching. When PPy was pyrolyzed between 400 and $600{ }^{\circ} \mathrm{C}$, the peaks located at 1727 and $1121 \mathrm{~cm}^{-1}$ disappeared, which means the $\mathrm{C}-\mathrm{O}-\mathrm{C}$ bonds were cleaved $[23,24]$. The intensity of the peaks located at 1594 and $844 \mathrm{~cm}^{-1}$ decreased with the increase in pyrolysis temperature but did not totally disappear. The peaks at $3034 \mathrm{~cm}^{-1}$ (C-H stretching of benzene) is still visible for PPy-400 and PPy-500, meaning the pyrene is preserved after pyrolysis. In addition, the peak at $875 \mathrm{~cm}^{-1}$ corresponds to the substitution of benzene in PPy, even after pyrolysis at 400 and $500{ }^{\circ} \mathrm{C}$. The other peak located at $755 \mathrm{~cm}^{-1}$ is attributed to the vibration of the methylene of the main chain. These results demonstrate that adjusting the pyrolysis procedure temperature for PPy can control the decomposition of the polymer and prevent fully carbonization of the polymer precursors. In the Raman spectra of the SiO-PPy-T composites (Figure 1c), two prominent peaks at 1340 and $1605 \mathrm{~cm}^{-1}$ were observed that correspond to the D and G band, respectively. Normally, the intensity ratio of the D and G bands $\left(I_{\mathrm{D}} / I_{\mathrm{G}}\right)$ is used to determine defective disorders in the crystalline graphite or quality of graphitization. A lower $\mathrm{I}_{\mathrm{D}} / \mathrm{I}_{\mathrm{G}}$ ratio indicates better graphitization. For SiO-PPy-400, 500, and 600, the $I_{\mathrm{D}} / I_{\mathrm{G}}$ ratios were $0.65,0.55$, and 0.60 , respectively, indicating that sintering at $500{ }^{\circ} \mathrm{C}$ resulted in the highest degree of graphite. To further understand the structure changes of PPy during pyrolysis, X-ray photoelectron spectroscopy (XPS) was used for analysis (Figure 1d-h). As shown in the C 1s spectra, the peaks corresponding to $\mathrm{C}-\mathrm{O}, \mathrm{C}-\mathrm{C}, \mathrm{C}=\mathrm{C}$, and $\mathrm{C}=\mathrm{O}$ were found on the surface of the PPy and the pyrolyzed products, which agree with the ATR-FTIR results. The $\mathrm{C}=\mathrm{C}$ content had a decreasing trend with the increase in temperature, which was almost the same at both 400 and $500{ }^{\circ} \mathrm{C}$. The major difference lies in the spectra of $\mathrm{C} 1 \mathrm{~s}$ at $500{ }^{\circ} \mathrm{C}$ : an extra peak was observed around $292.1 \mathrm{eV}$ that was attributed to the delocalized sp $2 \pi$ bonding, which enables good electronic conductivity [25,26]. This is also consistent with the Raman results: a stronger relative $\mathrm{G}$ band of the sample treated at $500{ }^{\circ} \mathrm{C}$ indicates a higher degree of ordered structure than the other samples. Therefore, we chose to focus the remainder of our material characterization on samples pyrolyzed at $500{ }^{\circ} \mathrm{C}$.

The morphology of the composite samples was characterized by scanning electron microscopy (SEM) as shown in Figure S1. Compared with the pure SiO, SiO-PPy-500 has a similar structure before and after coatings. The particle size ranged from a few hundred nanometers to about one micrometer. When increasing the heating temperature to $500{ }^{\circ} \mathrm{C}$, the outer surface of the particles became smoother after coating. The SiO-PPy-500 microstructure was further characterized by high-resolution transmission electron microscopy (HRTEM). The SiO particles were successfully coated with a layer of carbon with a thickness around $15 \mathrm{~nm}$ (Figure 2b). Notably, an ordered structure was observed on the edge of the particles. Based on previous research on the PPy polymer by our group, the ordered domains result from the $\pi-\pi$ stacking of the pyrene units of the polymer. Additionally, an ordered precursor more easily creates a high graphite structure during sintering. Additional support for this uniform coating of the carbon layer is demonstrated by the dark-field scanning transmission electron microscopy (STEM) image and Energy-dispersive X-ray spectroscopy (EDX) mappings (Figure 2c). The results confirm that $\mathrm{SiO}$ was indeed wrapped by carbon. The elemental mapping images of silicon, carbon, and oxygen clearly demonstrate the uniform distribution of $\mathrm{SiO}$ in a carbon matrix. The Raman spectra of SiO-PPy-500 and pure $\mathrm{SiO}$ are shown in Figure $2 \mathrm{~d}$. A broad peak extending from 424 to $508 \mathrm{~cm}^{-1}$, with a peak at $465 \mathrm{~cm}^{-1}$, was observed, corresponding to the amorphous $\mathrm{SiO}$. Additionally, two prominent peaks were observed at 1340 and $1605 \mathrm{~cm}^{-1}$, which correspond to the D and G bands, respectively. Figure 2e shows the XRD patterns of pure SiO particles and the composite samples of SiO-PPy-500. No diffraction peaks for pure $\mathrm{SiO}$ and $\mathrm{SiO}-\mathrm{PPy}-500$ were observed, confirming the amorphous structure of the samples, and the lack of silicon carbide formation for the SiO-PPy-500 composite. 


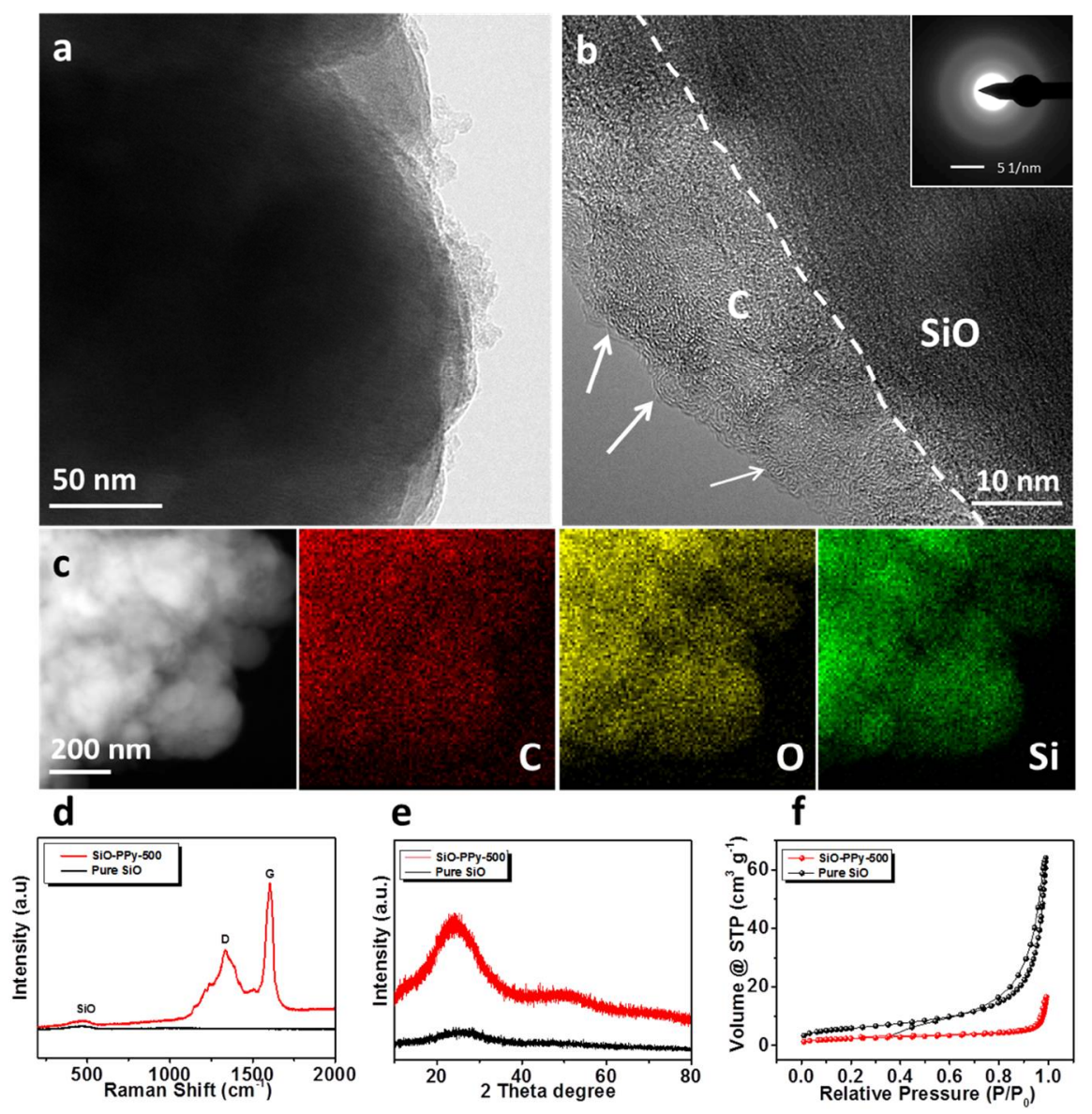

Figure 2. (a,b) High-resolution transmission electron microscopy (HRTEM) images of SiO-PPy-500. The top insert is the Selected Area Electron Diffraction (SAED) of the carbon; (c) Energy-dispersive X-ray spectroscopy (EDX) mapping of SiO-PPy-500; (d) Raman spectra of pure $\mathrm{SiO}$ and SiO-PPy-500; (e) x-ray diffraction (XRD) spectra of pure $\mathrm{SiO}$ and $\mathrm{SiO}-\mathrm{PPy}-500$ samples; and (f) the adsorption-desorption isotherm of pure $\mathrm{SiO}$ and $\mathrm{SiO}-\mathrm{PPy}-500$ composite.

The surface areas of the $\mathrm{SiO}-\mathrm{PPy}-500$ composite and pure $\mathrm{SiO}$ were studied by $\mathrm{N}_{2}$ adsorption/desorption measurement (Figure 2f). According to the results, pure $\mathrm{SiO}$ has a surface area of $21.1 \mathrm{~m}^{2} / \mathrm{g}$. After coating with PPy and pyrolysis, the surface area decreased to $8.6 \mathrm{~m}^{2} / \mathrm{g}$ for SiO-PPy-500, which can be attributed to extensive pore plugging due to the PPy pyrolysis. The low surface area helps to decrease the side reactions of SiO. Thermogravimetric analysis (TGA) was performed to identify the content of $\mathrm{SiO}$ in the composite samples. The TGA curve of SiO-PPy-500 in air is shown in Figure S2. The residual mass of SiO-PPy-500 at $700{ }^{\circ} \mathrm{C}$ is about $88.35 \mathrm{wt} \%$. In addition, a slight weight increased occurred after $700{ }^{\circ} \mathrm{C}$, indicating the oxidation of $\mathrm{SiO}$ under high temperatures.

To evaluate the electrochemical performance of the SiO-PPy-500 composite, 2325-type coin cells were fabricated and the areal mass loading of $\mathrm{SiO}$ composite was controlled to be approximately $1.6-1.9 \mathrm{mg} / \mathrm{cm}^{2}$. Cyclic voltammetry $(\mathrm{CV})$ was conducted between 2.0 and $0.01 \mathrm{~V}$ with a scan rate of $0.1 \mathrm{mV} / \mathrm{s}$, as shown in Figure S3. A very weak cathodic peak appeared at $1.0-0.5 \mathrm{~V}$ (vs. $\mathrm{Li} / \mathrm{Li}+$ ) in the first onset, which is attributed to the SEI formation due to the reaction of the electrolyte with the surface of the active materials. The main cathodic peak in the first cycle, between 0.25 and $0.01 \mathrm{~V}$, is attributed to the alloying of crystalline $\mathrm{Si}$ to form amorphous $\mathrm{Li}_{\mathrm{x}} \mathrm{Si}$ phase. From the second cycle onward, a new cathodic peak appeared at $\sim 0.1 \mathrm{~V}$, indicating the reversible lithiation of the a-Si domains. Two anodic peaks were clearly observed at about 0.54 and $0.38 \mathrm{~V}$. These peaks are associated with the 
de-alloying of the $\mathrm{Li}_{x} \mathrm{Si}$. As the scan proceeded, the intensity of the anodic peaks increased, indicating the occurrence of the activation process of the sample.

The electrochemical properties of SiO-PPy-500 composite and pure $\mathrm{SiO}$ were systematically compared, and all the reported capacities in the half cell were calculated based on the mass of SiO. Its galvanostatic discharge-charge curves were obtained with a voltage window between 0.01 and $1.0 \mathrm{~V}$ versus $\mathrm{Li} / \mathrm{Li}^{+}$(Figure 3a) at a current rate of $0.05 \mathrm{C}$ for the first cycle $(1 \mathrm{C}=1000 \mathrm{~mA} / \mathrm{g}$ current density). During the first SiO-PPy-500 discharge process, a broad and long slope rises with the voltage, ranging from 0.9 to $0.01 \mathrm{~V}$ in the first discharge, consistent with the electrochemical behavior of the typical Si-based composite electrode. The flat plateau at $\sim 0.4 \mathrm{~V}$ is ascribed to the formation of SEI [27]. The SiO-PPy-500 has outstanding first discharge/charge capacity at 2058.6/1280 mAh/g (Figure 3a). Compared with an ICE of $54.8 \%$ for pure $\mathrm{SiO}$ (Figure S4), an enhanced ICE of $62.2 \%$ was recorded for SiO-PPy-500. The irreversible capacity loss is attributed to the formation of the SEI passivation film due to the irreversible reaction with electrolyte and the formation of $\mathrm{Li}_{2} \mathrm{O}$ and $\mathrm{Li}_{4} \mathrm{SiO}_{4}$ [28,29]. This might be solved by pre-lithiating the active materials. Figure $3 \mathrm{~b}$ shows the rate performance of pure $\mathrm{SiO}$ and $\mathrm{SiO}-\mathrm{PPy}-500$ electrodes cycled ranging from 0.1 to $2 \mathrm{C}$. The SiO-PPy-500 delivered a capacity of $1127.5 \mathrm{mAh} / \mathrm{g}$ at the rate of $0.1 \mathrm{C}$, and then gradually decreased to $649.9 \mathrm{mAh} / \mathrm{g}$ at the rate of $0.5 \mathrm{C}$, and $487.0 \mathrm{mAh} / \mathrm{g}$ at the rate of $1 \mathrm{C}$. Even at a high rate of $2 \mathrm{C}$, a reversible capacity of $317.6 \mathrm{mAh} / \mathrm{g}$ was still achieved. Notably, when the rate was restored to $0.1 \mathrm{C}$, the SiO-PPy-500 composite electrode showed a capacity of $1145.7 \mathrm{mAh} / \mathrm{g}$, completely recovering its initial capacity. The results are remarkably superior to that of pure $\mathrm{SiO}$, with a continuous capacity decrease at each current density in the same range. The results show that the SiO-PPy-500 displays an excellent rate performance with a stable cycling behavior at different current densities. Figure $3 \mathrm{c}$ and Figure S5 show the cycling stability of the SiO-PPy-500 composite electrodes and pure $\mathrm{SiO}$ electrode. After the first cycle at a rate of $0.05 \mathrm{C}$ for the formation step, the cells were then cycled at $0.1 \mathrm{C}$ over 50 cycles between 0.01 and $1.0 \mathrm{~V}$. The SiO-PPy-500 electrodes had much higher reversible specific capacities of $1090.2 \mathrm{mAh} / \mathrm{g}$ after 50 cycles than that of the pure electrodes, which was $771.6 \mathrm{mAh} / \mathrm{g}$ for the pure $\mathrm{SiO}$ electrode. The corresponding capacity retention was $83.5 \%$ vs. $66.9 \%$ based on the second cycle.

To investigate the mechanism for improving the electrochemical performance, electrochemical impedance spectra (EIS) measurement was completed on pure SiO- and SiO-PPy-500-based electrodes after discharge/charge for 50 cycles. As shown in Figure 3d, the charge transfer resistance of the $\mathrm{SiO}-\mathrm{PPy}-500$ electrode was significantly smaller than that of the SiO electrode, confirming that SiO-PPy-500 has better diffusion capability of $\mathrm{Li}^{+}$and higher electro-conductivity. Long-term cycling tests clearly showed the effect of the high graphitization carbon coatings on the cycle performance of the SiO-PPy-500 composite at a higher current rate (0.3 C) (Figure 3e). A higher specific capacity of $514.6 \mathrm{mAh} / \mathrm{g}$ after 500 discharge/charge cycles was achieved, which was much higher than that of traditional graphite anode materials. In addition, the SiO-PPy-500 demonstrated a rapid increase in stabilized efficiency greater than $99.5 \%$ after only five cycles, including the first formation cycle, and was very stable in the remaining cycles. This cycling efficiency result is quite promising for the assembly of alloy anodes into full cells.

We also changed the mass ratio of SiO and PPy to 8:2 to study the effect on the performance of the resulting composite electrodes. The results are shown in Figures S6 and S7. The specific capacity of this electrode was $1069.7 \mathrm{mAh} / \mathrm{g}$ after 50 cycles at $0.1 \mathrm{C}$, and $744.6 \mathrm{mAh} / \mathrm{g}$ after 200 discharge/charge cycles at $0.3 \mathrm{C}$. When SiO-PPy-500 (7:3) was used, the gravimetric capacity of SiO was lower due to the lower carbon content. The higher the carbon content in a pyrolyzed sample, the higher the electronic conductivity, and the better the resistance to volume expansion during the discharge/charge process.

In addition, sucrose, as conventional carbon coating material, was used and compared in this work (SiO-C-500). The cycling performance of this electrode is shown in Figure S8a. We found that the capacity of the conventional $\mathrm{SiO}-\mathrm{C}-500$ electrode was significantly lower when sucrose was used, at only $455.4 \mathrm{mAh} / \mathrm{g}$ after 50 cycles at $0.1 \mathrm{C}$. The charge transfer resistance of the $\mathrm{SiO}-\mathrm{C}-500$ electrode was significantly higher than that of the SiO-PPy-500 electrode (Figure S8b), demonstrating a higher 
charge transfer resistance of the interface and lower electric conductivity. This is because sucrose molecules do not have $\pi-\pi$ stacking structures; therefore, they cannot obtain high graphitization at a low sintering temperature. The amorphous carbon provides neither significantly improved conductivity of the $\mathrm{SiO}$ materials, nor surface protection for the $\mathrm{SiO}$ materials. (Figure S9).
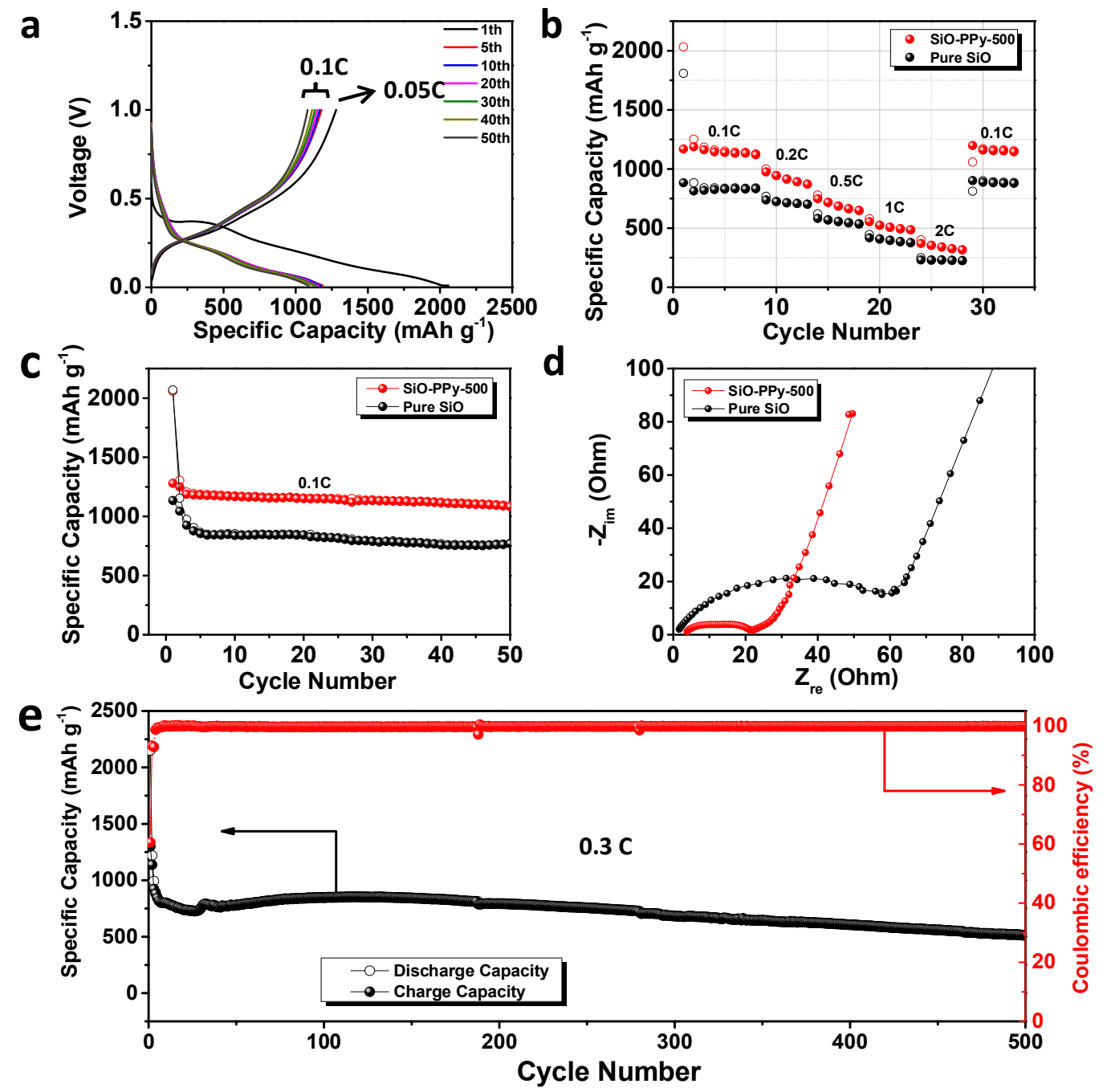

Figure 3. Electrochemical performance of the pure $\mathrm{SiO}$ and $\mathrm{SiO}-\mathrm{PPy}-500$ composite electrode: (a) discharge/charge profiles of SiO-PPy-500 measured at $0.05 \mathrm{C}$ for the first cycle and then $0.1 \mathrm{C}$ for 50 cycles; (b) the rate capabilities of pure $\mathrm{SiO}$ and $\mathrm{SiO}-\mathrm{PPy}-500$ at various current densities; (c) cycling performance at current densities of $0.1 \mathrm{C}$; (d) Nyquist plots of pure $\mathrm{SiO}$ and SiO-PPy-500 composite electrode after 50 cycles; and (e) long-term cycling performance of SiO-PPy-500 at the current rate of $0.3 \mathrm{C}$ for 500 cycles.

To further analyse the graphite carbon coating effect on the whole electrode during cycling, the cell was disassembled after 50 cycles at $0.1 \mathrm{C}$ and characterized by SEM, as shown in Figure 4 . The SEM image after 50 cycles shows the structural degradation of pure SiO (Figure $4 a, b)$. The electrode surface shows obvious cracking, and the laminate lost contact with the current collector. In contrast, from Figure $4 \mathrm{~d}$,e, the $\mathrm{SiO}-\mathrm{PPy}-500$ electrode features a flat and compact surface in a large domain, maintaining tight contact with the current collector under the same testing conditions. The highly improved cycling performance of the SiO-PPy-500 composite can be attributed to the high graphitization carbon coatings, which improve electron transport, and support fast Li diffusivity. In addition, the coating layer can act as a buffer layer to minimize the volume expansion of the 
$\mathrm{SiO}$ without rupture, thereby avoiding particle pulverization and loss of contact with carbon black or the current collector. By sharp contrast, no sub-micrometer particles were observed in the pure $\mathrm{SiO}$ electrode, indicating the serious pulverization of the $\mathrm{SiO}$ component. Without graphite carbon coatings, $\mathrm{SiO}$ particles cracked under stress of the dimensional changes, leading to degraded cycling performance.
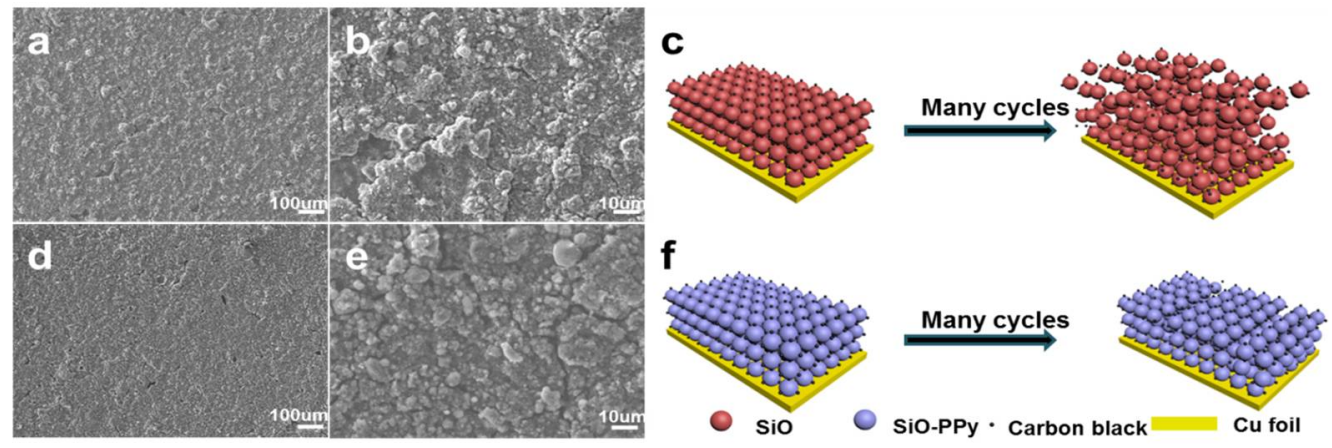

Figure 4. (a-c) Scanning electron microscopy (SEM) images and corresponding schematic illustration of the pure $\mathrm{SiO}$ electrode after 50 cycles at a current density of $0.1 \mathrm{C} ;(\mathbf{d}-\mathbf{f}) \mathrm{SEM}$ images and corresponding schematic illustration of SiO-PPy-500 electrode after 50 cycles at a current density of $0.1 \mathrm{C}$.

To evaluate the validity of the graphitization core-shell SiO-PPy-500 composite, upon integration with $\mathrm{Li}\left[\mathrm{Ni}_{0.5} \mathrm{Co}_{0.2} \mathrm{Mn}_{0.3}\right] \mathrm{O}_{2}$ (NCM) (half-cell data in Figure S10), full-cells were tested in the voltage range of 2.5 to $4.3 \mathrm{~V}$ at a current density of $1 \mathrm{C}$ for 90 cycles $(1 \mathrm{C}=160 \mathrm{~mA} / \mathrm{g})$ (Figure 5). Before assembling the full-cell, we prelithiated the anode electrode by introducing lithium ions into the $\mathrm{SiO}$ materials using electrical shorting with lithium metal foil in the electrolyte [30]. The detailed process is outlined in the experiment section. For the first cycle, the charge and discharge capacities were 142.2 and $123.5 \mathrm{mAh} / \mathrm{g}$, respectively, corresponding to an ICE of $86.6 \%$. After 90 cycles, the full cell delivered a discharge capacity of $93.7 \mathrm{mAh} / \mathrm{g}$, and the capacity retention was $75.9 \%$. We also calculated that the gravimetric energy density of this $\mathrm{SiO}-\mathrm{PPy}-500 / \mathrm{NCM}$ full-cell, considering the weight of the anode and cathode materials. From ED $=\left\{\left(C_{\text {cathode }} \times C_{\text {anode }}\right) /\left(C_{\text {cathode }}+C_{\text {anode }}\right)\right\} V_{\text {nominal }}$ [30], the capacity $\left(C_{\text {cathode }}=160 \mathrm{mAh} / \mathrm{g}\right.$ and $\left.C_{\text {anode }}=1090 \mathrm{mAh} / \mathrm{g}\right)$ and the voltage $(3.6 \mathrm{~V})$, our full-cell had an energy density of $502 \mathrm{Wh} / \mathrm{kg}$, which is much higher than the traditional graphite-based cell. This SiO-PPy-500-based electrode showed good electrochemical performance in the full-cell.
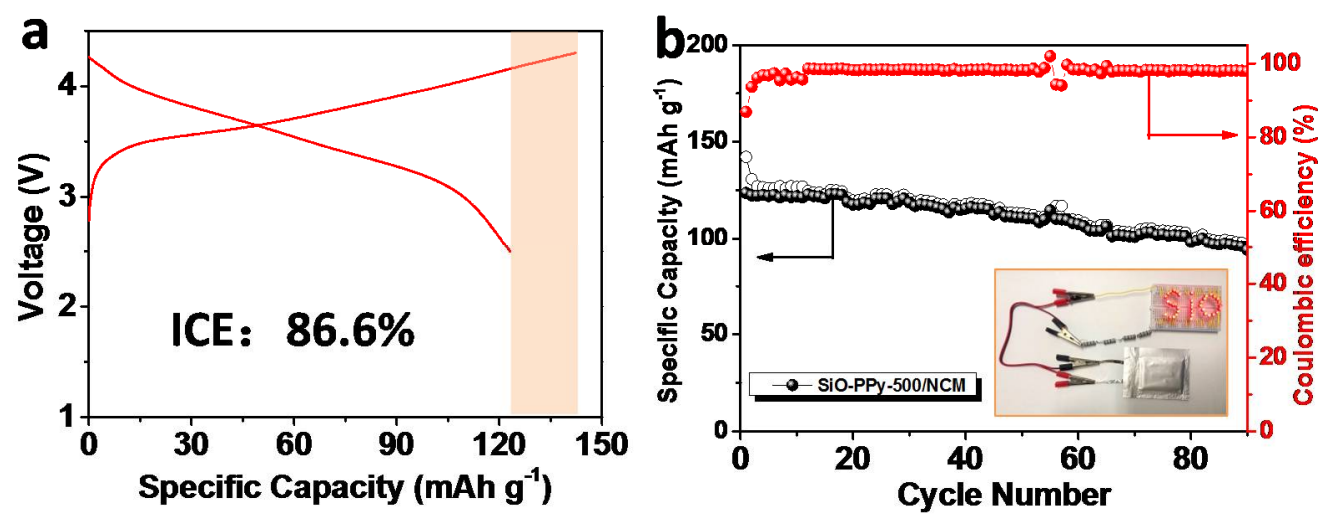

Figure 5. (a) Galvanostatic discharge/charge profiles of the prelithiated SiO-PPy-500 I NCM full-cell in the first cycles at $1 \mathrm{C}$ and (b) cycling performance for 90 cycles at $1 \mathrm{C}$. The inset shows an array of commercial red light-emitting diodes (LEDs) for $\mathrm{SiO}$ powered by the assembled full-cell. 


\section{Conclusions}

In summary, a $\pi-\pi$ stacked PPy polymer precursor was used as a coating for $\mathrm{SiO}$ materials. The pyrolysis of polymer coating at low to medium temperatures led to a highly graphitized coating on the $\mathrm{SiO}$ surface. The electrode based on $\mathrm{SiO}-\mathrm{PPy}-500$ material achieved excellent cycling stability. The pyrolyzed PPy coating on the surface of SiO formed a highly graphitized carbon layer that provided a conducting network on $\mathrm{SiO}$ materials and a robust layer to prevent electrolyte reaction with the $\mathrm{SiO}$ surface. The carbon layer maintained the conductivity of the electrode and acted as an excellent matrix to accommodate the volume expansion during the discharge/charge cycles. The $\pi-\pi$ stacked polymer precursor coating is a promising method to modify the surface of Si-based materials for high-capacity LIB anode applications.

Supplementary Materials: The following are available online at http:/ / www.mdpi.com/2073-4360/10/6/610/s1, Experiment details; SEM images of pure SiO; TGA analysis of SiO-PPy-500; discharge/charge curves of pure SiO at $0.1 \mathrm{C}$; cycling performance of NCM; TGA analysis and cycling performance of SiO-PPy-500 (SiO to PPy ratio is 8:2); Cycling performance of SiO-C-500; TEM characterization; and TGA analysis.

Author Contributions: S.F., T.Z. (Tianyue Zheng) and G.L. conceived and designed the experiments; S.F., N.L., T.Z. (Ting Zhang), and B.W. performed the experiments; T.Z. (Tianyue Zheng) synthesized the polymer; S.F., N.L. and G.L. analyzed the data; Y.F. and X.S. contributed NCM materials and performed the TEM experiments; S.F., T.Z. (Tianyue Zheng) and G.L. wrote the paper; S.L. and X.Z. joined the discussion.

Acknowledgments: G.L. acknowledges funding support from the Assistant Secretary for Energy Efficiency, Vehicle Technologies Office of the U.S. Department of Energy (U.S. DOE) under the Advanced Battery Materials Research (BMR), Applied Battery Research (ABR) Programs and Next Generation Anodes for Lithium-ion Batteries program. Electron microscopy experiments are conducted at the National Centre for Electron Microscopy (NCEM) located at Lawrence Berkeley National Laboratory and supported by the Director, Office of Science, Office of Basic Energy Sciences, of the U.S. Department of Energy under Contract No. DE-AC02-05CH11231. X.Z. acknowledges financial support by the National Program on Key Basic Research Project of China (973 Program, No. 2014CB239701), the National Natural Science Foundation of China (No. 51372116 and 51504139), the Natural Science Foundation of Jiangsu Province (No. BK2011030 and BK20150739).

Conflicts of Interest: The authors declare no conflict of interest.

\section{References}

1. Aurbach, D.; Levi, M.D.; Levi, E.; Teller, H.; Markovsky, B.; Salitra, G.; Heider, U.; Heider, L. Common electroanalytical behavior of $\mathrm{Li}$ intercalation processes into graphite and transition metal oxides. J. Electrochem. Soc. 1998, 145, 3024-3034. [CrossRef]

2. He, Y.B.; Tang, Z.Y.; Song, Q.S.; Xie, H.; Liu, Y.G.; Xu, Q. Effects of temperature on the formation of graphite/ $\mathrm{LiCoO}_{2}$ batteries. J. Electrochem. Soc. 2008, 155, A481-A487. [CrossRef]

3. Yi, R.; Dai, F.; Gordin, M.L.; Sohn, H.; Wang, D.H. Influence of Silicon Nanoscale Building Blocks Size and Carbon Coating on the Performance of Micro-Sized Si-C Composite Li-Ion Anodes. Adv. Energy Mater. 2013, 3, 1507-1515. [CrossRef]

4. Obrovac, M.N.; Krause, L.J. Reversible cycling of crystalline silicon powder. J. Electrochem. Soc. 2007, 154, A103-A108. [CrossRef]

5. Chan, C.K.; Peng, H.L.; Liu, G.; McIlwrath, K.; Zhang, X.F.; Huggins, R.A.; Cui, Y. High-performance lithium battery anodes using silicon nanowires. Nat. Nanotechnol. 2008, 3, 31-35. [CrossRef] [PubMed]

6. Beaulieu, L.Y.; Eberman, K.W.; Turner, R.L.; Krause, L.J; Dahn, J.R. Colossal reversible volume changes in lithium alloys. Electrochem. Solid State Lett. 2001, 4, A137-A140. [CrossRef]

7. Obrovac, M.N.; Christensen, L. Structural changes in silicon anodes during lithium insertion/extraction. Electrochem. Solid State Lett. 2004, 7, A93-A96. [CrossRef]

8. Liu, N.; Wu, H.; McDowell, M.T.; Yao, Y.; Wang, C.M.; Cui, Y. A Yolk-Shell Design for Stabilized and Scalable Li-Ion Battery Alloy Anodes. Nano Lett. 2012, 12, 3315-3321. [CrossRef] [PubMed]

9. Su, H.P.; Barragan, A.A.; Geng, L.X.; Long, D.H.; Ling, L.C.; Bozhilov, K.N.; Mangolini, L.; Guo, J.C. Colloidal Synthesis of Silicon-Carbon Composite Material for Lithium-Ion Batteries. Angew. Chem. Int. Ed. 2017, 56, 10780-10785. [CrossRef] [PubMed] 
10. Liu, Y.J.; Tai, Z.X.; Zhou, T.F.; Sencadas, V.; Zhang, J.; Zhang, L.; Konstantinov, K.; Guo, Z.P.; Liu, H.K. An All-Integrated Anode via Interlinked Chemical Bonding between Double-Shelled-Yolk-Structured Silicon and Binder for Lithium-Ion Batteries. Adv. Mater. 2017, 29. [CrossRef] [PubMed]

11. Lin, D.C.; Lu, Z.D.; Hsu, P.C.; Lee, H.R.; Liu, N.; Zhao, J.; Wang, H.T.; Liu, C.; Cui, Y. A high tap density secondary silicon particle anode fabricated by scalable mechanical pressing for lithium-ion batteries. Energy Environ. Sci. 2015, 8, 2371-2376. [CrossRef]

12. Lin, J.; He, J.R.; Chen, Y.F.; Li, Q.; Yu, B.; Xu, C.; Zhang, W.L. Pomegranate-Like Silicon/Nitrogen-doped Graphene Microspheres as Superior-Capacity Anode for Lithium-Ion Batteries. Electrochim. Acta 2016, 215, 667-673. [CrossRef]

13. Yang, L.Y.; Li, H.Z.; Liu, J.; Sun, Z.Q.; Tang, S.S.; Lei, M. Dual yolk-shell structure of carbon and silica-coated silicon for high-performance lithium-ion batteries. Sci. Rep. 2015, 5, 10908. [CrossRef] [PubMed]

14. Wu, H.; Chan, G.; Choi, J.W.; Ryu, I.; Yao, Y.; McDowell, M.T.; Lee, S.W.; Jackson, A.; Yang, Y.; Hu, L.B.; et al. Stable cycling of double-walled silicon nanotube battery anodes through solid-electrolyte interphase control. Nat. Nanotechnol. 2012, 7, 309-314. [CrossRef] [PubMed]

15. Park, M.H.; Kim, M.G.; Joo, J.; Kim, K.; Kim, J.; Ahn, S.; Cui, Y.; Cho, J. Silicon Nanotube Battery Anodes. Nano Lett. 2009, 9, 3844-3847. [CrossRef] [PubMed]

16. Yao, Y.; McDowell, M.T.; Ryu, I.; Wu, H.; Liu, N.A.; Hu, L.B.; Nix, W.D.; Cui, Y. Interconnected Silicon Hollow Nanospheres for Lithium-Ion Battery Anodes with Long Cycle Life. Nano Lett. 2011, 11, 2949-2954. [CrossRef] [PubMed]

17. Du, F.H.; Ni, Y.Z.; Wang, Y.; Wang, D.; Ge, Q.; Chen, S.; Yang, H.Y. Green Fabrication of Silkworm Cocoon-like Silicon-Based Composite for High-Performance Li-Ion Batteries. ACS Nano 2017, 11, 8628-8635. [CrossRef] [PubMed]

18. Chen, S.Q.; Shen, L.F.; van Aken, P.A.; Maier, J.; Yu, Y. Dual-Functionalized Double Carbon Shells Coated Silicon Nanoparticles for High Performance Lithium-Ion Batteries. Adv. Mater. 2017, 29. [CrossRef] [PubMed]

19. Wu, H.; Yu, G.H.; Pan, L.J.; Liu, N.A.; McDowell, M.T.; Bao, Z.A.; Cui, Y. Stable Li-ion battery anodes by in-situ polymerization of conducting hydrogel to conformally coat silicon nanoparticles. Nat. Commun. 2013, 4, 1943. [CrossRef] [PubMed]

20. Piper, D.M.; Yersak, T.A.; Son, S.B.; Kim, S.C.; Kang, C.S.; Oh, K.H.; Ban, C.M.; Dillon, A.C.; Lee, S.H. Conformal Coatings of Cyclized-PAN for Mechanically Resilient Si nano-Composite Anodes. Adv. Energy Mater. 2013, 3, 697-702. [CrossRef]

21. Lee, D.J.; Ryou, M.H.; Lee, J.N.; Kim, B.G.; Lee, Y.M.; Kim, H.W.; Kong, B.S.; Park, J.K.; Choi, J.W. Nitrogen-doped carbon coating for a high-performance $\mathrm{SiO}$ anode in lithium-ion batteries. Electrochem. Commun. 2013, 34, 98-101. [CrossRef]

22. Park, S.J.; Zhao, H.; Ai, G.; Wang, C.; Song, X.Y.; Yuca, N.; Battaglia, V.S.; Yang, W.L.; Liu, G. Side-Chain Conducting and Phase-Separated Polymeric Binders for High-Performance Silicon Anodes in Lithium-Ion Batteries. J. Am. Chem. Soc. 2015, 137, 2565-2571. [CrossRef] [PubMed]

23. Majeed, S.; Filiz, V.; Shishatskiy, S.; Wind, J.; Abetz, C.; Abetz, V. Pyrene-POSS nanohybrid as a dispersant for carbon nanotubes in solvents of various polarities: Its synthesis and application in the preparation of a composite membrane. Nanoscale Res. Lett. 2012, 7, 296. [CrossRef] [PubMed]

24. Chen, W.L.; Peng, Y.F.; Chiang, S.K.; Huang, M.H. Thermal properties and physicochemical behavior in aqueous solution of pyrene-labeled poly(ethylene glycol)-polylactide conjugate. Int. J. Nanomed. 2015, 10, 2815-2822.

25. Wu, H.; Cui, Y. Designing nanostructured Si anodes for high energy lithium ion batteries. Nano Today 2012, 7, 414-429. [CrossRef]

26. Szczech, J.R.; Jin, S. Nanostructured silicon for high capacity lithium battery anodes. Energy Environ. Sci. 2011, 4, 56-72. [CrossRef]

27. Chan, C.K.; Ruffo, R.; Hong, S.S.; Cui, Y. Surface chemistry and morphology of the solid electrolyte interphase on silicon nanowire lithium-ion battery anodes. J. Power Sources 2009, 189, 1132-1140. [CrossRef]

28. Wang, J.; Zhao, H.L.; He, J.C.; Wang, C.M.; Wang, J. Nano-sized SiOx/C composite anode for lithium ion batteries. J. Power Sources 2011, 196, 4811-4815. [CrossRef] 
29. Takezawa, H.; Iwamoto, K.; Ito, S.; Yoshizawa, H. Electrochemical behaviors of nonstoichiometric silicon suboxides (SiOx) film prepared by reactive evaporation for lithium rechargeable batteries. J. Power Sources 2013, 244, 149-157. [CrossRef]

30. Kim, H.J.; Choi, S.; Lee, S.J.; Seo, M.W.; Lee, J.G.; Deniz, E.; Lee, Y.J.; Kim, E.K.; Choi, J.W. Controlled Prelithiation of Silicon Monoxide for High Performance Lithium-Ion Rechargeable Full Cells. Nano Lett. 2016, 16, 282. [CrossRef] [PubMed] 